S.P. Novosyadliy, V.M Lukovkin, R. Melnyk A.V. Pavlyshyn

\title{
Physical-Topology Modeling of Silicon/Gallium Arsenide Schottky Transistor of Submicron Technology LSI
}

\author{
Vasyl Stefanyk Precarpathian National University, Ivano-Frankivsk, Ukraine, kkie@ pu.if.ua
}

\begin{abstract}
In this paper researched essentials and physical mechanisms of MESFET on epitaxy layers of GaAs with monocrystalline silicon wafer is described. Computer modeling of MESFET with p-channel: distributions of potential, volumetric charge, current in channel and its characteristics is conducted. Based on conducted modeling new effect in MESFET, shielding of volumetric charge, which sufficiently influences on current distribution in channel is discovered.
\end{abstract}

Key words: electronics, LSI, MESFET, modelling, GaAs.

Received 17 February 2020; Accepted 15 June 2020.

\section{Introduction}

Today existing theory of field transistor and its model, which was developed by Shockley and it based on smooth change of thickness, doesn't satisfy submicron technology LSI, by which fast transistors formed on epilayers of GaAs, precipitated on monosilicon wafers. Nowadays there is no united and systemized picture of functioning of field transistor, despite appearance of complementary MESFETS on homojunction and heterojunction. Thus, the aim of our research is adjustment of mechanisms of FET work, with two-dimensional physical-topology model.

\section{Physical-topology model and its boundary conditions}

Two-dimensional model of field-effect transistor is considered based on its geometrical structure, which shown in Fig. 1. It is also considered that all physical processes in stationary mode of work of FET with p-type channel are described by fundamental mathematical system of equations which for internal description $0 \leq \mathrm{x} \leq 1,0 \leq \mathrm{y} \leq \mathrm{h}$ look like these:

$$
\begin{gathered}
-\mathrm{j}=-\mathrm{qp} \mu \operatorname{grad}(\mathrm{U})-\mathrm{qDgrad}(\mathrm{n}) \operatorname{div}(\mathrm{j})=0 ; \\
\operatorname{div}(\operatorname{grad}(\mathrm{U}))=\frac{\mathrm{q}}{\varepsilon}\left(\mathrm{p}-\mathrm{N}_{\mathrm{A}}\right),
\end{gathered}
$$

where $\mathrm{j}$ - full current density of hole current, $\mathrm{q}-$ charge of epilayer, p-concentration of holes, $\mu-$ mobility of holes, D - coefficient of hole diffusion $\varepsilon-$ relative permittivity, $\mathrm{U}-$ potential, $N_{A}-$ concentration of acceptors. It is needed to add to these equations famous Einstein relation $\mathrm{D}=\mu \frac{k T}{q}$. As it is known, functional dependency of mobility of charge carriers determined by material of semiconductor $(\mathrm{Ga}, \mathrm{Si}, \mathrm{GaAs})$. The modeling of MESFETS on mono-Si was conducted with a fair approximation: $\mu=\frac{\mu_{0}}{1+\mu_{0} E v_{f}}-$ mobility of holes in weak fields, E - electric field in channel; $v_{f}$ - highest velocity of holes in mono-Si.

Boundary and initial conditions for our modeling expressed with next equations:

$$
\begin{aligned}
& -\mathrm{U}=0, \mathrm{x}=0,0 \leq \mathrm{y} \leq \mathrm{U} ; \\
& -\quad \mathrm{U}=\mathrm{U}_{\mathrm{d}}, \mathrm{x}=1,0 \leq \mathrm{y} \leq \mathrm{U} ; \\
& -\quad \mathrm{p}=0, \mathrm{U}=\mathrm{U}_{\mathrm{g}}, l_{s-g} \leq \mathrm{x} \leq l_{s-g}+l_{g}, \mathrm{y}=0 ; \\
& -\quad \frac{\partial U}{\partial y}=0,0 \leq \mathrm{x} \leq 1, \mathrm{y}=\mathrm{U}, 0 \leq \mathrm{x} \leq l_{s-g}, \\
& \quad l_{s-g}+l_{g} \leq \mathrm{x} \leq l_{g}, \mathrm{y}=0 ;
\end{aligned}
$$

Considered and showed by us distributions of potentials, volumetric charges and current density in MESFET channel - this is result of numerical modeling and solution of the nonlinear system determined above. There should be considered action of isotype $p^{+}-p$ or $n^{+}-n$ drain-source junctions, formed with dual multicharge implantation for reducing resistance of drain 
and source and increasing steepness of MESFET. Except this now there should be considered processes of epitaxial deposition $\mathrm{p}$ of $\mathrm{n}$-layers GaAs on monosilicon wafers because these two processes increasing, at least, by order speed of formed MESFET and based on it allow forming complementary pairs which significantly decreasing power consumption of submicron LSI.

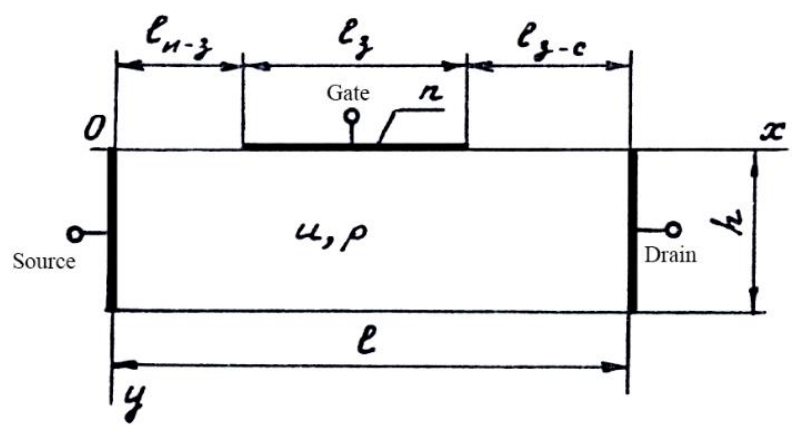

Fig.1. Two-dimensional computing area of MESFET model.

\section{Results of modeling of parameters of MESFETS: distribution of potential, volumetric charge and current density in transistor structure}

As you can see from the representation of equations for modeling and their boundary conditions, current in MESFET structure depends on gradient of potential U, gradient of concentration profile of holes. Therefore we are going to examine influence of these variables on work of MESFET. It worth noting that potential - is independent variable and its value on electrodes can be changed in certain places. So at option of potentials on electrodes in our example distribution of potential in channel will be changing and consequently, distribution of holes concentration also will be changing. For good clarity, for modeling processes in MESFET structure, shown on Fig. 1, we will assume that channel uniformly doped with acceptors with concentration, and junction (Schottky barrier) gate-channel is steep and concentration of impurities in gate is bigger by several orders than concentration of impurities in channel because gate formed on film from aluminum alloy AlSiHo-11. Geometrical sizes of test structure were chosen as following: $l_{s-g}=l_{s-d} \leq 5 \mu \mathrm{m}, l_{g}=1 \mu \mathrm{m}$.

Based on above information, it was examined redistribution of potential in MESFET during creation of volumetric charge. Let voltage on gate $U_{3}=U_{3-\text { в }}+$ $\varphi_{k}=2.8 V\left(\varphi_{k}-\right.$ Schottky barrier $)$, and potentials of source and drain equal zero. Therefore output distribution of potential until creation of volumetric charge described by equation: $\operatorname{div}(\operatorname{grad}(\mathrm{U}))=\mathrm{q} \cdot \varepsilon(\mathrm{p}-$ $N_{A}$ ) and characterized by uniform decrease of potential from gate to drain-source electrodes.

On Fig. $2 \mathrm{a}$ is shown the result of $U$ distribution as dashed line and symmetry of characteristics falls. Electric field $E=\operatorname{grad}(\mathrm{U})$, which formed with gate voltage, will be repelled holes from undergate area, which will lead to creation of volumetric charge.
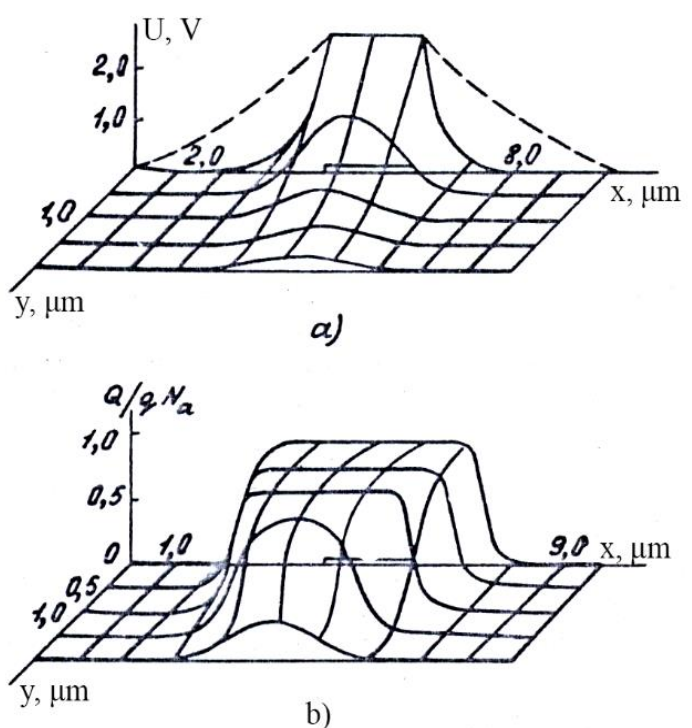

Fig. 2. Distribution of potential (a) and volumetric charge (б) in structure.

Thereby created volumetric charge creates own electric field which gradually with distance from gate to some extent compensate primary field of gate. Result of distribution of potential $U$ is shown in Fig. 2a (solid lines) and distribution of volumetric charge on Fig. $2 b$. Length of volumetric charge restricted in such a way that beyond of its border field created by it and field of gate fully compensate. This means that borders of volumetric charge and potential relief under absence of movable charge carriers should match. Experiment fully confirms this fact. Due to diffusion of holes junction from fully impoverished area to neutral area of semiconductor is smooth enough. Herewith in neutral area of semiconductor potential becomes constant, so it's gradient equals zero. There is worth noting that if under absence of volumetric charge field of gate spread throughout all MESFET structure, but under volumetric charge field localizing in undergate area. Thereby created volumetric charge shields neutral MESFET area from influence of gate potential.

Matching of borders of volumetric charge and potential relief during absence of current sometimes considered as incorrect understanding of current flow mechanisms in MESFET channel. It is supposed that channel in which current flow can be restricted by volumetric charge. Actual obstacle can be potential barrier. There cannot be affirmed that current cannot flow through area of volumetric charge. But it can flow in direction of increase of potential U. And holes, which got to area of volumetric charge, freely roll off on slope of created relief.

If negative voltage is applied to source then resulting distribution of potential created by voltages applied to gate and drain, and unmovable volumetric charge and movable holes. On Fig. 3 given distribution of potential under voltage on source $U_{d-s}=-5$. Main distinction of this distribution, unlike Fig. 2a, is potential slope, between drain and source, on which holes are moving and creating channel current. Thereby area in which flows current (channel), is restricted by slopes of 


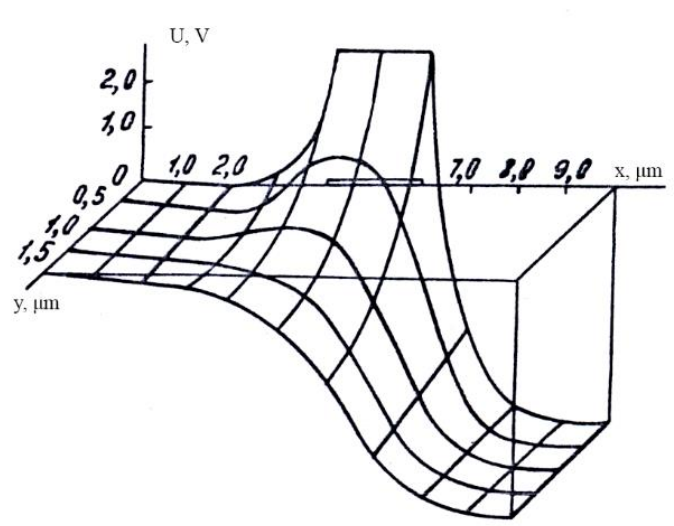

Fig. 3. Potential relief in MESFET structure during current flow.

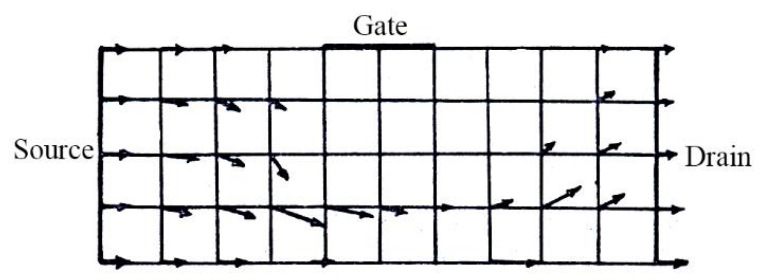

Fig. 4. Distribution of current in MESFET channel.

potential relief. In its movement from source to drain holes will flow around potential hill, which formed by gate, thus created channel will be thin and in area of gate. Since holes are trying to occupy position with minimal potential then spreads of current density on channel are already uneven (roundabout). On Fig. 4 by arrows is shown distribution of current density, and length and direction of each arrow characterizes current density and current direction in according points of channel.

\section{Modeling of MESFET characteristics: input, output, transfer}

Let us follow for example of forming output characteristics of MESFET during change of voltage on gate and drain and related with it changing distribution of potential. There we will assume that mobility of charge carriers in channel is constant and doesn't depend on electric field.

At first, we need to examine stage of process of MESFET, under absence of voltage on drain potential of gate is not big enough for overlapping of transistor with volumetric charge. Under comparison Fig. 2a and 3, it is visible that under certain constant potential of gate increasing of voltage on drain facilitates transfer of holes from source to drain, since during this process slope of potential relief, between source and drain, increasing and holes easier roll off to drain. At the same time dependency of current from voltage is nonlinear. Under small voltages on drain, until volumetric charge doesn't overlap channel, current will be increasing quickly. Under high voltage on drain which corresponds to full overlap of channel with volumetric charge, increasing of current is slowing down, in other words here formed pentode characteristic. This is due to the fact that significant part of potential of drain is spending on expanse of area of volumetric charge between gate and drain and we can interpret this as shielding of channel and drain area from influence of drain by volumetric charge. Then because of this main part of drain voltage fall on volumetric charge area in gate-drain area and only insignificant part fall on drain area. In result gradient of potential which created in drain area by drain potential and MESFET current depend from degree of shielding, value doesn't increasing much with expanse of volumetric charge during increasing of drain potential.

The conclusion follows from this, during forming nonlinear output characteristic of MESFET main factor is not cooling direction of current flow of volumetric charge but shielding effect of its charge of channel and drain area of MESFET. Here shielding by volumetric charge takes place under presence as well as absence of current in channel.

In real MESFETs on reviewed mechanism is imposing influence of dependence of mobility of charge carriers from electric field in channel. Herewith, despite increasing concentration of charge carriers from electric field in channel with increasing voltage on drain, drain current can not only saturating uniformly but also have very interesting area of negative resistance. It allows to use such MESFETS as autogenerators.

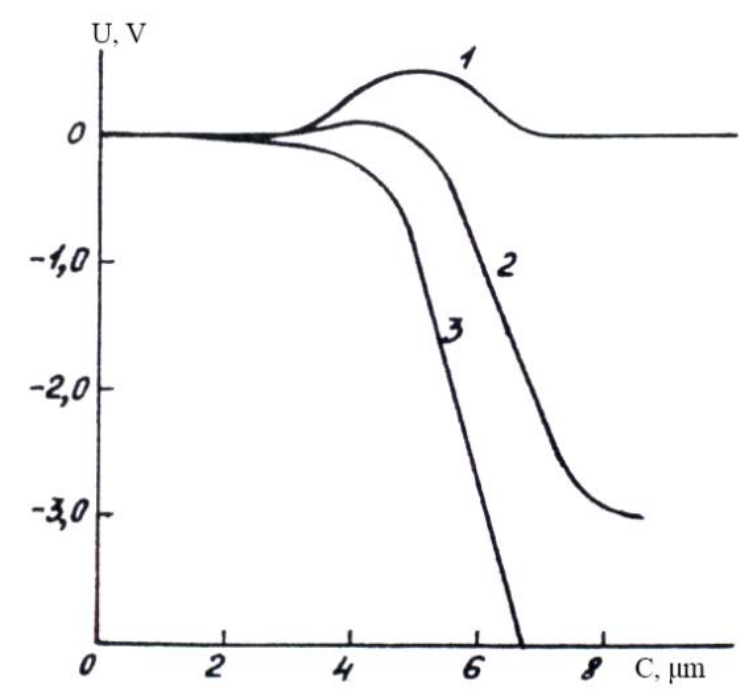

Fig.5. Distribution of potential in excision $y=h$ under different voltages on drain.

Let follow now process of redistributing of potential and creation of channel in MESFET, which in output state is closed by outer voltage on gate or by potential difference gate-channel. As it shown on Fig. 2a under $U_{d-s}=0$ volumetric charge spread in all depth of MESFET channel, which in profile transistor corresponds $\mathrm{y}=\mathrm{h}$, where takes place potential barrier for holes between drain and source and there is no current in device(Fig. 5 curve 1 under $U_{g-s}=4 \mathrm{~V}$ ). And now if we apply voltage on drain then volumetric charge in area of gate-drain expands even more to source area. But decreasing of potential on drain decreases potential barrier between source and drain. Curve 2 on Fig. 5 exactly shows case, that corresponds to voltage 
$U_{d-s}=-3 \mathrm{~V}$, when barrier decreased but its value is still unreachable for holes and there is no current in MESFET. Here shielding effect of volumetric charge manifests itself in case that to decrease potential barrier to zero then it's needed to apply somewhat high voltage. Indeed, furthermore increasing of voltage on drain leads to decreasing of Schottky barrier until its extinction, firstly in excision $\mathrm{y}=\mathrm{h}$, and then in more wide area, until creation of channel, on which holes rolling off to drain (Fig. 5, curve 3, $U_{d-s}=-10 \mathrm{~V}$ ). Created in such way output characteristic can be identified as triode-like.

As we see, practically current in MESFET appears when potential barrier still exist but it is so small that most energetic charge carriers already can overcome it, after that they rolling off to drain. Here it worth noting that sufficient effect in this case responsible for junction of current, from output to barrier, is diffusion component of current and from barrier to drain - drift component of current. It's important for understanding of speed of MESFET.

In MESFET with small distance source-drain(short channel $L_{g}<1 \mu \mathrm{m}$ ) influence of drain potential on height of barrier, in other words controllability from drain side, shows itself strongly shielded with volume of charge from influence of current. Hence, for opening closed MESFET, it's needed to apply on gate such high potential, even larger than punch-through voltage. In other words, triode-likeness of output characteristics, particulary controllability from drain side, shows itself in such MESFETs only ending value of output resistance in saturation area, and this means that drain-source junctions need to be formed isotype, kind $p^{+}-p$ or $n^{+}-n$, using dual multicharge implementation.

So in result of modeling of MESFET discovered effect of shielding which sufficiently influences on forming of its characteristics and speed.

\section{Conclusions}

Based on conducted research it is possible to make the next conclusions:

1. Conducted computer modeling of MESFET with p-channel: distributions of potential, volumetric charge, current in channel and its characteristics.

2. Based on conducted modeling discovered new effect in MESFET, shielding of volumetric charge, which sufficiently influences on current distribution in channel.

3. Discovered effect of shielding allows forming MESFETS with output characteristic with present negative resistance which especially useful for autogenerators.

Novosyadly S.P. - Dr. Sci. (technical sciences), professor of the department of computer engineering and electronics;

Lukovkin V.M. - PhD student;

Melnyk R. - PhD student;

Pavlyshyn A.V. - student.

[1] T. Mizutani, Japanese Journal of Applied Physics (1982).

[2] V.I. Sen'ko, M.V. Panasenko, Electronics and microcircuitry (Oberehy, Kyiv, 2000).

[3] M. Shur, Modern devices based on GaAs (Mir, Moscow, 1991).

[4] F. Tian, E.F. Chor, Thin Solid Films 518(24), 121 (2010).

[5] M.J. Sikder, P. Valizadeh, Solid-State Electronics 89, 105 (2013).

[6] V.A. Moskalyuk, D.I. Timofeev A.V. Fedyaj, Ultrafast electronic devices (NTUU KPI, Kyiv, 2012).

\author{
С.П. Новосядлий, В.М. Луковкін, Р. Мельник, А.В. Павлишин
}

\title{
Фізично-топологічне моделювання кремнісвого/арсенідгалісвого транзистора Шотткі субмікронної технології ВIC
}

\author{
Прикарпатський національний університет імені Василя Стефаника, \\ м. Івано-Франківськ, Украӥна, kkiе@ри.іf.иа
}

\begin{abstract}
В даній статті описані досліджені основи і фізичні механізми, арсенідгалієвих ПТШ на моно-Siпідкладках на бар'єрі Шотткі. Проведено комп'ютерне моделювання ПТШ з р-каналом: розподілів потенціалу, об'ємного заряду, струму в каналі та його характеристик. На основі проведеного моделювання відкрито новий ефект в ПТШ, а саме екранування об'ємного заряду, що суттєво впливає на струмовий розподіл в каналі.
\end{abstract}

Ключові слова: електроніка, BIC, Польові транзистори Шотткі, моделювання, GaAs. 